DOI: 10.12731/2070-7568-2019-1-41-56

УДК 338.5

\title{
АНАЛИЗ ПОВЕДЕНИЯ РОССИЙСКИХ ПОТРЕБИТЕЛЕЙ ПАРФЮМЕРИИ И КОСМЕТИКИ
}

\author{
Прохорова М.П., Булганина С.В., Булганина А.Е., \\ Белоусова К.В.
}

В статье дано описание результатов маркетингового исследования сети магазинов парфюмерии и косметики. Целью данной работы разработка рекомендаџий для совершенствования маркетинговой политики розничных торговцев косметикой на основе анализа результатов проведенного опроса. При проведении исследования использовались социологические и статистические методы исследований.

Новизна полученных результатов работы заключается в уточнении важных для маркетинговой деятельности характеристик покупателей, таких как источники получения информации о магазинах парфюмерии и косметики и факторы их выбора, осведомленность клиентов о характеристиках парфюмерно-косметической продукции и заинтересованность их в новинках, лояльность покупателей к магазинам сети и оценка их конкурентоспособность. Сделаны выводы, что наибольшая доля покупателей предпочитает продукиию среднего и массового сегмента, а наиболее эффективными способами продвижения являются наружная реклама и информация в сети интернет. В качестве основных выводов указаны тенденции индивидуализации «масс-маркета» и усиления внимания клиентов к качеству сервиса. Результаты работы представляют практический интерес для разработки решений в области маркетинговой деятельности компании.

Ключевые слова: маркетинг; магазин; парфюмерия; косметика; потребитель. 


\section{ANALYSIS OF THE BEHAVIOR OF RUSSIAN CONSUMERS OF PARFY-MEASURES AND COSMETICS}

\section{Prokhorova M.P., Bulganina S.V., Bulganina A.E., Belousova K.V.}

The article describes the results of a marketing research of a network of perfumery and cosmetics stores. The purpose of this work was the description of the results of a survey of customers of perfumery and cosmetics shops, which help to clarify the marketing policy of a chain of stores. In conducting the study, sociological and static research methods were used.

The novelty of the results obtained is to clarify the characteristics of buyers that are important for marketing activities, such as sources of information about perfumery and cosmetics stores and factors of their choice, customer awareness of the characteristics of perfumery and cosmetic products and their interest in new products, customer loyalty to the chain stores and evaluation their competitiveness. It was concluded that the largest share of buyers prefer products of the medium and mass segment, and outdoor advertising and information on the Internet are the most effective means of promotion. The main conclusions are the trends of individualization of the "mass market" and increasing customer attention to the quality of service. The results of the work are of practical interest for the development of solutions in the field of marketing activities of the company.

Keywords: marketing; score; perfumery; cosmetics; consumer.

\section{Введение}

Российский рынок парфюмерии и косметики характеризуется в настоящее время интенсивным развитием $[1,3]$. Среди тенденций развития рынка парфюмерии и косметики можно выделить:

- устойчиво высокий спрос на косметику среднего и масссегментов;

- активное формирование новых торговых марок;

- активизация розничной он-лайн торговли; 
- увеличение доли косметической продукции, реализуемой через посредников;

- возрастание доли товаров для «здорового образа жизни» и пр. $[6,7]$.

Перечисленные изменения на рынке парфюмерии и косметики связаны с рядом тенденции этого рынка, важных с позиций маркетинга:

- потребитель, его предпочтения и потребности, становится ключевой фигурой при принятии решений о выпуске новых продуктов или формировании брендов;

- продвижение косметической продукции становится все более направленным на индивидуальное консультирование и привлечение медицинских специалистов, а вместе с тем высокотехнологичным, затратным, аналитически обоснованным;

- большую ценность приобретают реальная эффективность косметических средств и продуктов, отзывы и обратная связь от потребителей, высокое качество обслуживания $[8,10]$.

Все эти тенденции парфюмерно-косметического рынка позволяют судить о его значительном изменении: усилении конкурентной борьбы, смещении спроса в сторону масс-маркета (в связи с сокращением уровня реальных доходов населения и ростом цен на товары из-за роста курса доллара), распространении новых, более сложных стратегий ухода за лицом и телом. В связи с этим актуальность приобретают исследования, посвященные анализу ситуации на рынке парфюмерии и косметики, сегментации этого рынка, изучению потребительского поведения, продвижению брендов и поддержке эффективных маркетинговых решений $[2,4,5,9]$.

Целью данной работы выступает разработка рекомендаций для совершенствования маркетинговой политики розничных торговцев косметикой на основе анализа результатов проведенного опроса. Задачи исследования:

1. Выявить и проранжировать источники получения информации о магазинах парфюмерии и косметики и факторы их выбора;

2. Оценить осведомленность покупателей о характеристиках парфюмерно-косметической продукции и заинтересованность их в новинках; 
3. Определить уровень лояльности покупателей к магазинам сети и оценить их конкурентоспособность.

Подобные маркетинговые исследования позволяют решить ряд вопросов, связанных с оценкой рыночных перспектив продуктов и услуг, оценкой эффективности деятельности компании на рынке, проводить мониторинг изменений потребностей и предпочтений покупателей, вырабатывать эффективные способы противодействия конкурентам и принимать обоснованные маркетинговые решения.

\section{Материалы и методы исследования}

Исследование магазинов парфюмерии и косметики было осуществлено для сети магазинов, реализующих широкий набор косметических и парфюмерных продуктов в различных ценовых и потребительских сегментах. Исследование проводилось на базе региональной сети в г. Н. Новгороде, данная сеть имеет 8 точек в г. Н. Новгород и Нижегородской области, опросом было охвачено 6 торговых точек.

Исследования было проведено в октябрь-ноябре 2018 г. Торговая сеть действует в сегменте «масс-маркет». Сбор информации был проведен методом анкетирования, заполнение анкет осуществлялось покупателями сети магазинов лично (анкета предлагалась на кассе после покупки) и в электронной форме на сайте магазина. Всего в исследовании приняли участие 128 человек, 98 из которых женщины и 30 - мужчины. Сводка по респондентам представлена в таблице 1.

Таблицуа 1.

Сводка по респондентам, принявшим участие в исследовании

\begin{tabular}{|l|c|c|}
\hline & Женщины & Мужчины \\
\hline Число анкет, заполненных на кассе & 72 & 18 \\
\hline Число анкет, заполненных на сайте & 26 & 12 \\
\hline
\end{tabular}

Обработка информации осуществлялась с использованием статистических методов - ранжирование полученных результатов, расчет средних значений и их анализ. 


\section{Результаты исследования}

Основным фактором выбора магазина парфюмерии и косметики большинство опрошенных назвали уровень цен (рисунок 1). На втором месте - широта ассортимента, система скидок. Немаловажным является рекомендации друзей и знакомых.

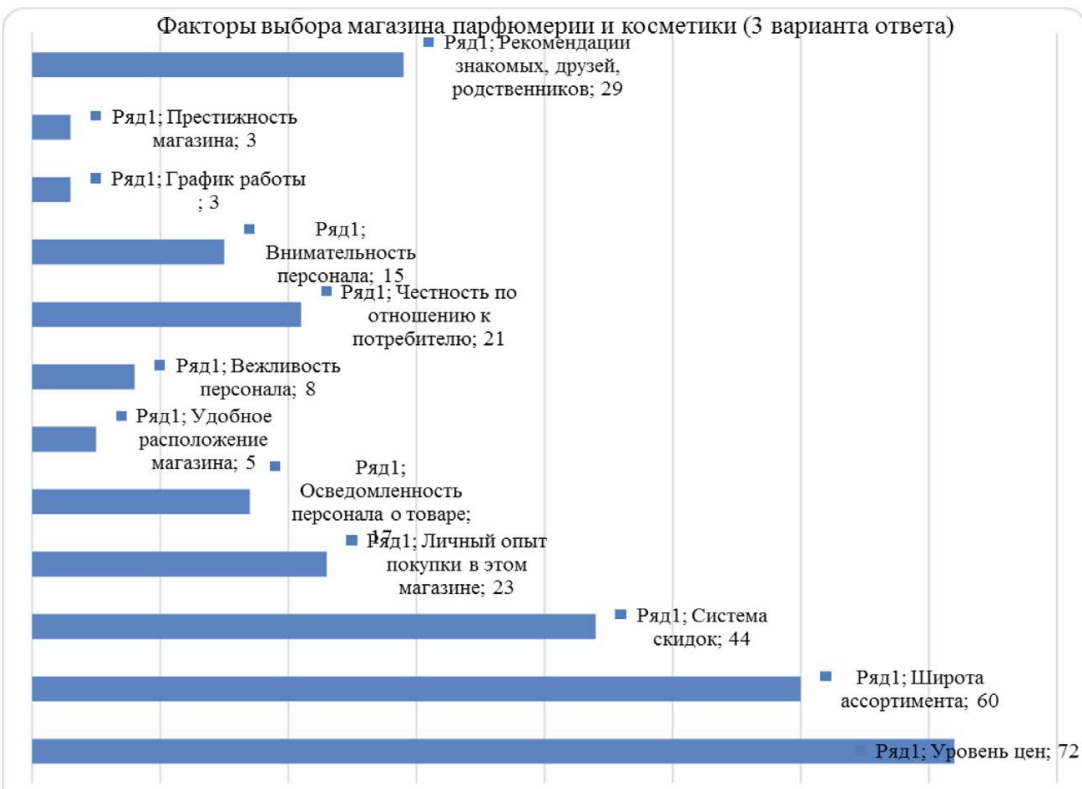

Рис. 1. Факторы выбора магазина парфюмерии и косметики

Одним из самых популярных источников информации о магазинах парфюмерии и косметики опрошенные получают из наружной рекламы, в дальнейшем покупки либо совершаются повторно, либо покупатель больше не приходит (рисунок 2).

Второй по популярности информации - блоги, социальные сети, а также новостные и тематические сайты. Данные источники информации превалируют и в выборе конкретного бренда косметического или парфюмерного средства (рисунок 3). Реклама на радио, телевидении и в печатных изданиях, несмотря на свою стоимость, замыкает рейтинг полученных ответов. 


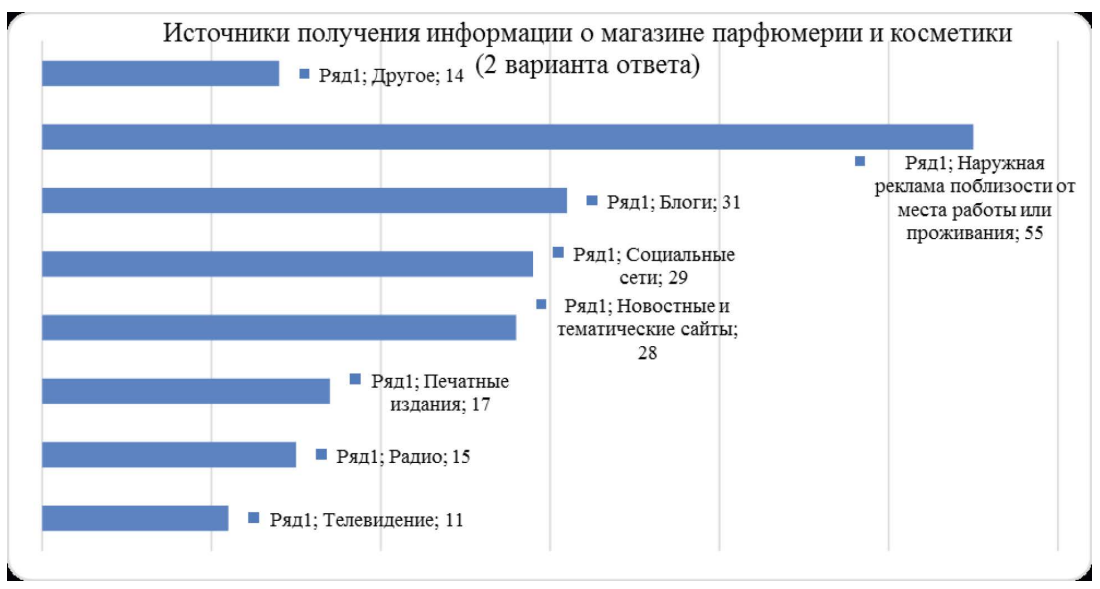

Рис. 2. Источники получения информации о магазине

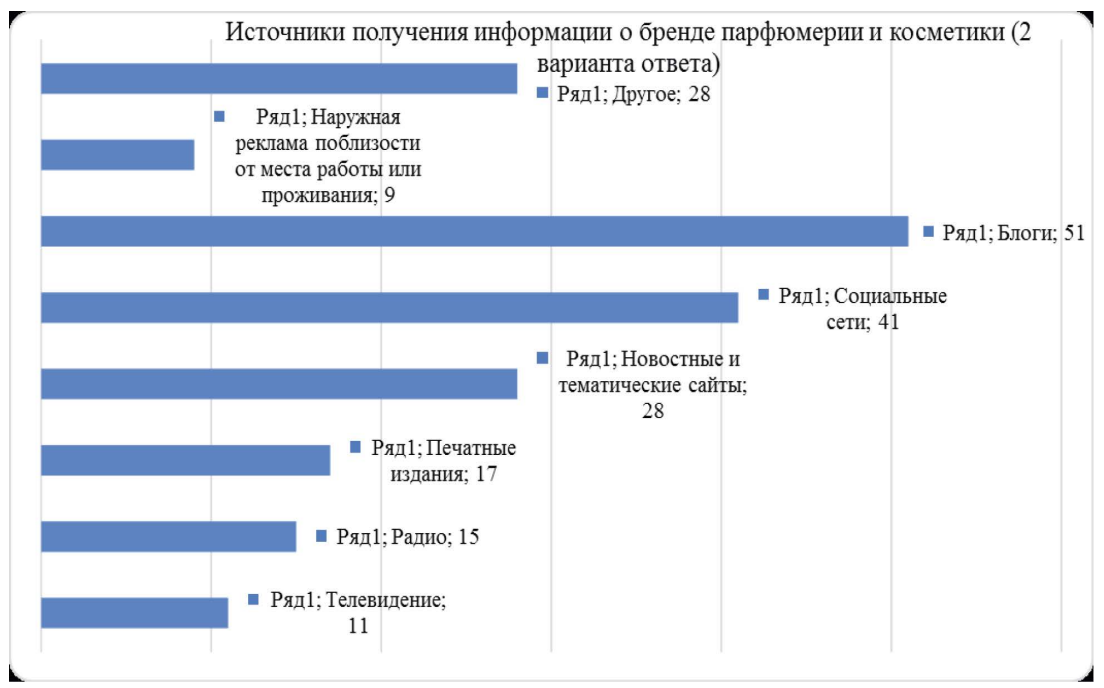

Рис. 3. Источники получения информации о бренде

Опрос показал низкую осведомленность о качествах и свойствах применяемой респондентами косметики и парфюмерии. 65\% опрошенных приобретают те или иные марки импульсивно или по привычке (рисунок 4). 


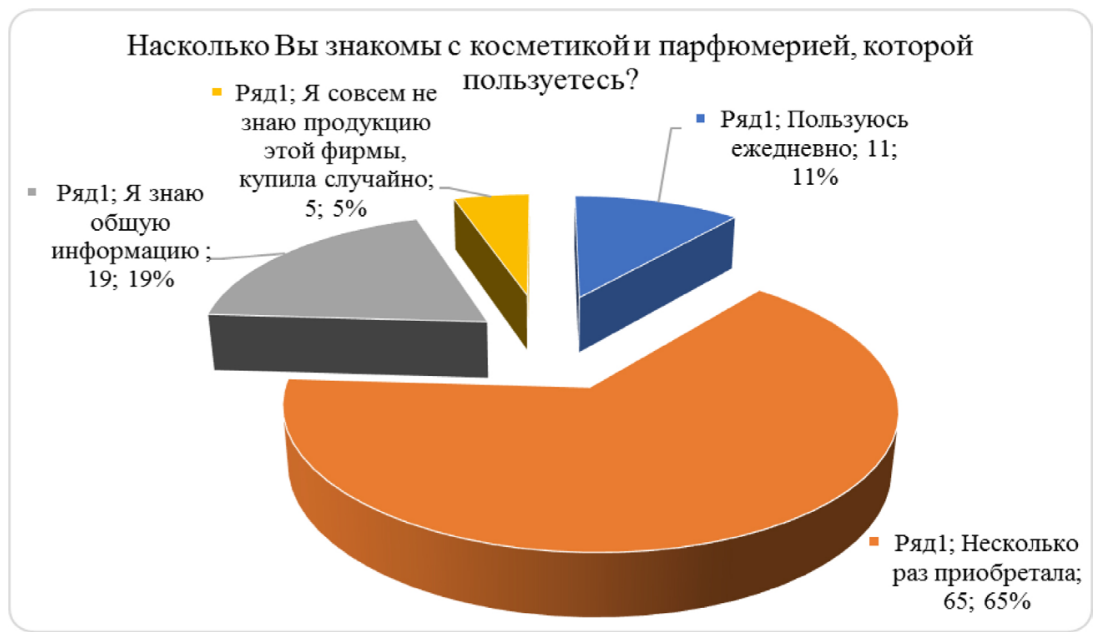

Рис. 4. Результаты ответа на вопрос об осведомленности применяемой косметики и парфюмерии

Общую информацию об используемых средствах имеют 19\% опрошенных. Эти данные повышают значимость работы консультанта в магазине, как эксперта по вопросам, связанным с правильным подбором средств.

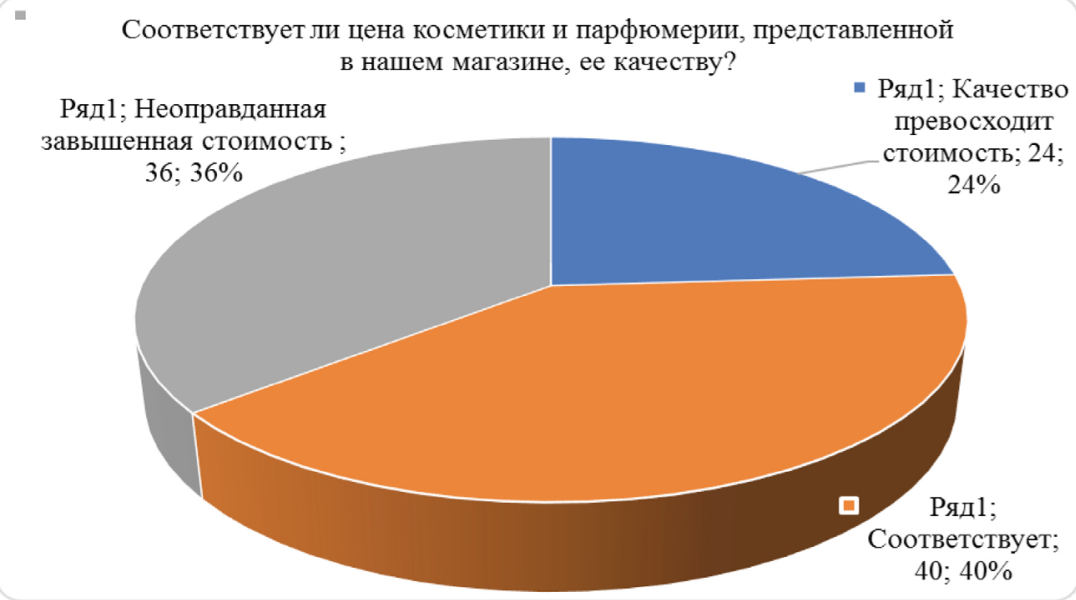

Рис. 5. Оценка соответствия цены и качества ассортимента 
Оценка, которую дали респонденты по параметру соответствия цены и качества ассортимента сети магазинов говорит о достаточно сбалансированной ценовой политике компании (рисунок 5).

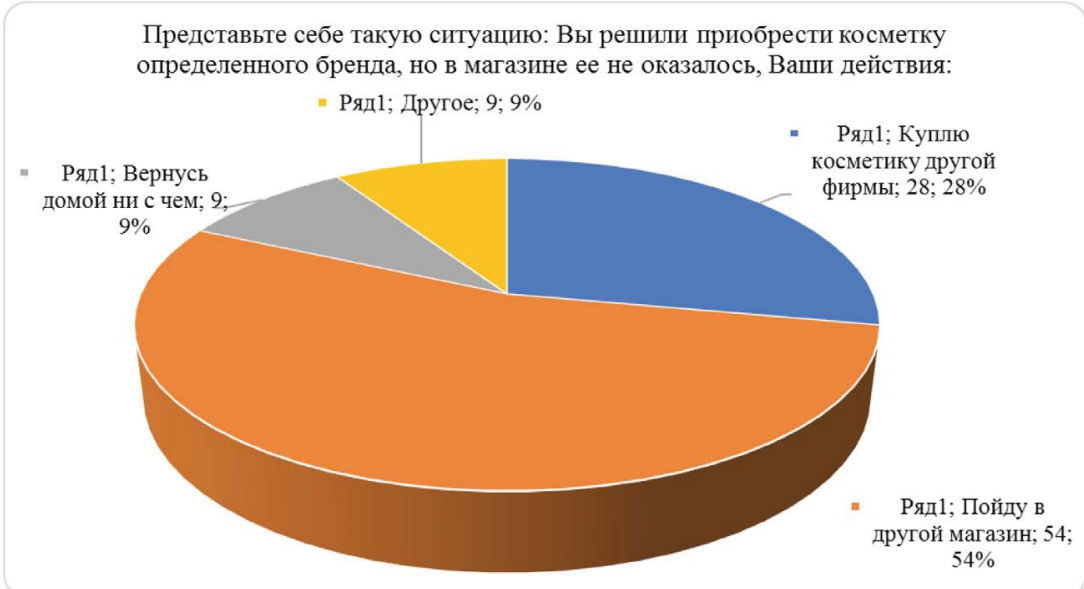

Рис. 6. Оценка степени лояльности к магазинам сети

Как часто Вы хотите видеть новинки в ассортименте нашего магазина?

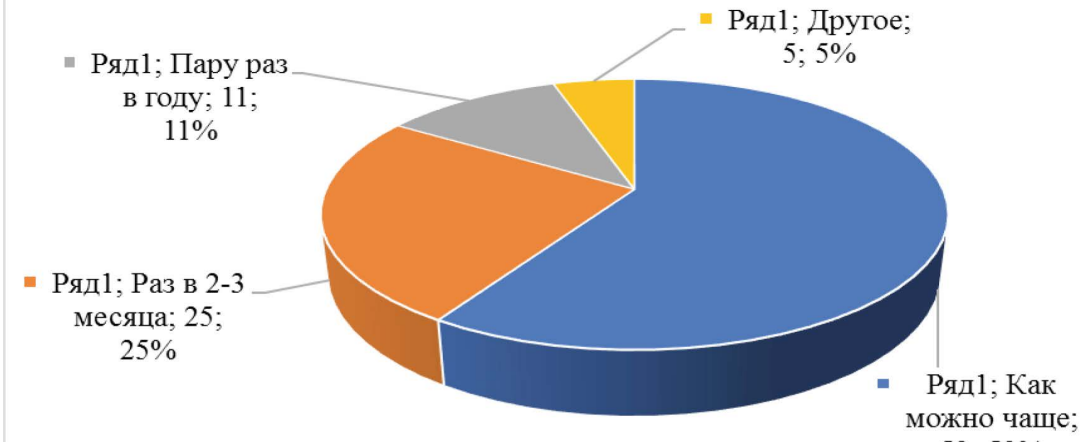

$59 ; 59 \%$

Рис. 7. Заинтересованность опрошенных в новинках сети магазинов

Косвенно оценить степень лояльности покупателей к бренду сети магазинов можно оценить по вопросу о приобретении конкретно- 
го бренда, которого не оказалось по каким-то причинам в магазине. Больше половины опрошенных (54\%) пойдут в другой магазин (рисунок 6). В этом случае малоэффективными окажутся попытки продавца-консультанта подобрать косметику другой марки.

Опрос показал высокую заинтересованность опрошенных в новинках сети магазинов (рисунок 7). 59\% опрошенных хотели бы видеть новинки как можно чаще. Еще 25\% хотели бы видеть новинки 2-3 раза в месяц.

Степень лояльности покупателей может быть также оценена с помощью оценки ключевых параметров конкурентоспособности торгового предприятия. По результатам оценки опрошенных наивысший балл из пяти возможных (таблица 3 и рисунок 8) - 4,4 получил такой параметр как известность магазина. Более 4 баллов получили такие параметры как оперативность обслуживания, удобство графика работы, широта ассортимента, гибкая система скидок, красивый интерьер.

Таблицуа 3.

Оценка конкурентоспособности сети магазинов

\begin{tabular}{|l|c|}
\hline \multicolumn{1}{|c|}{ Параметр } & $\begin{array}{c}\text { Средний } \\
\text { балл }\end{array}$ \\
\hline В этом магазине вежливый персонал & 3,18 \\
\hline В этом магазине внимательный персонал & 3,51 \\
\hline В этом магазине оперативное обслуживание & 4,17 \\
\hline В этом магазине честное отношение к потребителю & 3,07 \\
\hline В этом магазине удобный график работы & 4,3 \\
\hline В этом магазине приемлемый уровень цен & 3,18 \\
\hline Есть удовлетворенность от личного опыта покупки в этом магазине & 3,87 \\
\hline В этом магазине хорошая осведомленность персонала о характеристиках & 3,65 \\
\hline и особенностях товара & 4,09 \\
\hline В этом магазине широкий ассортимент & 4,04 \\
\hline В этом магазине есть выгодная система скидок & 4,07 \\
\hline В этом магазине красивое оформление & 4,4 \\
\hline Этот магазин известный & 3,19 \\
\hline Этот магазин рекомендовали друзья и родственники & 3,75 \\
\hline Итого & \\
\hline
\end{tabular}

Однако показатели, которые непосредственно характеризуют сервис в магазине, находятся на довольно низком уровне. Так, веж- 
ливость персонала опрошенные оценили только на 3,18 балла, уровень цен - на 3,18, осведомленность персонала о характеристиках и особенностях товара - на 3,65 балла.

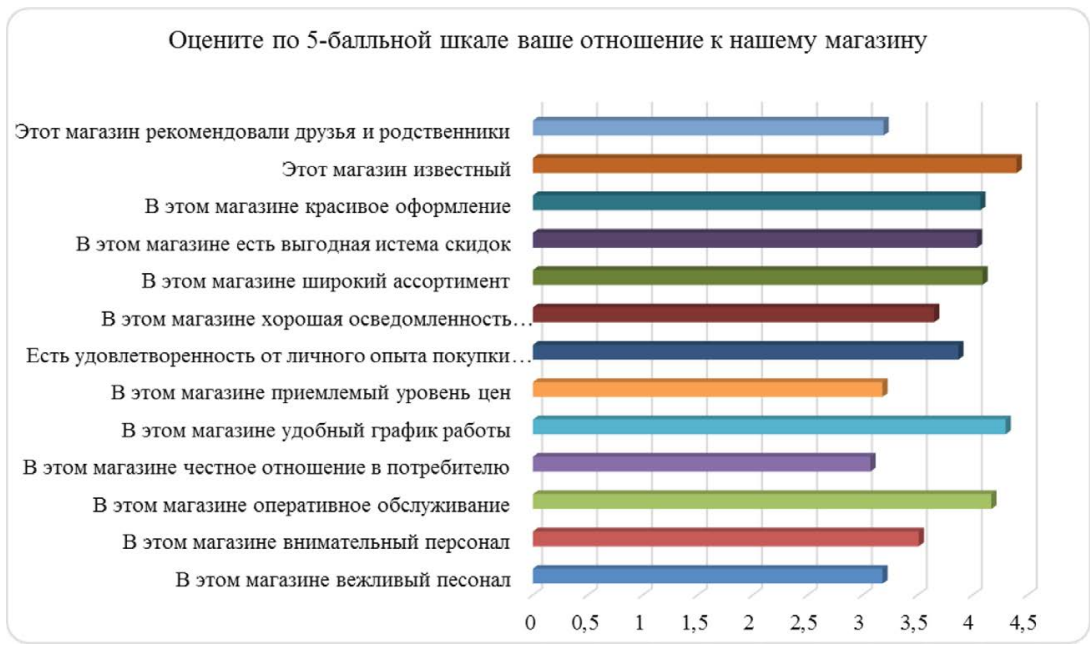

Рис. 8. Оценка конкурентоспособности сети магазинов

В целом ни по одному из показателей магазины сети не набрали 5 баллов, что негативно влияет на имидж компании. Далее представлялось интересным уточнить характеристики потребителейреспондентов, оказывающих основное влияние на использование средств косметики и парфюмерии. Уже с 16 лет девушки становятся потребителями декоративной косметики. Однако в целом выделяется два возрастных типа активных женщин-потребителей: девушки в возрасте 18-20 лет и женщины 25-35 лет (35\%).

По социальному статусу выделяется два типа женщин-потребителей. Первый тип - самый активный - это неработающая женщина, домохозяйка, чаще всего молодая мама (совокупных доход семьи составляет от 15000 до 35000 р.). Второй тип - это служащая или специалист, но не занимающая руководящей должности (совокупный доход семьи составляет свыше 35000 руб.). Женщины-руководители, наоборот, не очень склонны к частому и активному ис- 
пользованию декоративной косметики. Марка становится основным фактором выбора косметики для молодой женщины-потребителя в возрасте до 35 лет.

Целевую группу выборки, на которой проводился опрос, составили на 76\% женщины, и 24\% мужчин. В основном портреты потребителя и покупателя совпадают. Однако надо учитывать, что, например, 2-3\% покупателей декоративной косметики - мужчины, а их доля среди постоянных потребителей декоративной косметики близка к $0 \%$. И женщины, и мужчины активно пользуются средствами по уходу за кожей. Доля женщин, пользующихся средствами по уходу за кожей, во всех возрастных группах примерно одинаковая. Ту же ситуацию можно наблюдать и среди мужчин: доли мужчин, использующих средства по уходу за кожей, в возрасте 16 лет и 54 года примерно равны.

\section{Обсуждение}

Полученные в ходе исследования данные имеют прикладную значимость, поскольку позволяют сформулировать ряд важных закономерностей в поведении и предпочтениях потребителей сети магазинов парфюмерии и косметики.

Во-первых, наибольшее влияние на потребителей сети магазинов оказывают уровень цен, ассортимент, система скидок и внимательное и компетентное отношение к клиенту. Большинство покупателей стремятся приобрести решение проблемы по относительно невысокой стоимости из «масс-сегмента», что обуславливает необходимость поиска изменения схем обслуживания в сторону активизации личного консультирования.

Во-вторых, основное влияние на выбор магазинов оказывает известность сети (по наружной рекламе) и степень её представления в Интернет на сайтах, блогах и социальных сетях. Следовательно, эти инструменты остаются самыми эффективными в плане продвижения.

В-третьих, для большинства покупателей характерна низкая осведомленность о характеристиках приобретаемых продуктов, а также ориентация на бренд. Потребность покупателей в более высокой 
осведомленности о продуктах и новинках открывает новые возможности, связанные с привлечением внимания и индивидуальным консультированием.

\section{Заключение}

В целом по результатам проведенной работы можно предложить ряд рекомендаций для совершенствования маркетинговой политики розничных торговцев косметикой.

1. В условиях интенсивного развития Интернет-торговли следует обратить внимание на возможности тематических сайтов, блогов и социальных сетей для продвижения бренда магазина;

2. Основное влияние на потенциальных покупателей парфюмерии и косметики оказывает наличие гибкой ценовой политики, развитая система скидок, а также приверженность большей доли покупателей определенной марке. Этим фактам стоит уделить особое внимание при совершенствовании маркетинговой деятельности.

3. Наиболее важным фактором покупки выступает положительный опыт использования определенной марки, сочетающийся с интересом к новинкам. Это подтверждает важность консультативной поддержки покупателей со стороны продавцов и производителей косметики и парфюмерии.

4. Среди характеристик качества обслуживания необходимо обратить внимание на удобство расположения магазинов, известность бренда и оперативность обслуживания.

6. Перспективным направлением становится развитие информационной поддержки постоянных клиентов (посредством социальных сетей, смс-оповещения и пр.), обеспечивающей их индивидуальное консультирование.

\section{Список литературы}

1. Абдуллаева А.А. Рынок косметических средств в России: выбор и предпочтения россиян // Научное сообщество студентов XXI столетия. Экономические науки: сб. ст. по мат. LXVII междунар. студ. науч.- 
практ. конф. № 7(67). URL: https://sibac.info/archive/economy/7(67).pdf (дата обращения: 22.03.2019) (дата обращения: 10.01.2019).

2. Алиева 3.М. Концепция формирования потребительского поведения под влиянием маркетинга отношений в розничной торговле // TERRA ECONOMICUS. 2013. T. 11. №4.2. C. 92-99.

3. Вахтеева Д.А. Особенности российского рынка косметических средств // Молодой ученый. 2015. № 21 (101). С. 367-369.

4. Голованова Е. Модель анализа люксовых брендов в интернете на примере парфюмерно-косметического рынка // Маркетинговые коммуникации. 2018. №3. С. 234-242.

5. Кривдина О.А. Актуализация современных подходов к сегментации парфюмерно-косметического рынка // Современные тенденции экономики и управления: Материалы международной научно-практической конференции. Курский институт кооперации. 2016. С. 215-219.

6. Махмудова Р. М. Развитие парфюмерно-косметического рынка России и рекламная активность // Реклама. Теория и практика. 2009. №5. С. 274-284.

7. Николаева М.А., Ний А.А. Анализ состояния и тенденций парфюмерно-косметического рынка в России // Экономические исследования. 2017. [Электронный ресурс]. URL: http://www.erce.ru/internetmagazine/magazine/49/706/ (дата обращения: 10.01.2019).

8. Фадеева Т.П., Монаков Ю.И. Тенденции изменения структуры рынка парфюмерно-косметических товаров в России // Экономика и управление в XXI веке: тенденции развития. 2016. № 29. С. 119-123.

9. Цветкова А., Маркин И. Продвижение парфюмерно-косметических брендов в сегменте российской молодежной аудитории // Маркетинговые коммуникации. 2018. №2. С. 104-111.

10. Черницова М.А. Тенденции рынка парфюмерно-косметической продукции за период с 2005 по 2016 гг. // Журнал научных статей Здоровье и образование в XXI веке. 2017. Т. 19. No 8. С. 189-191.

\section{References}

1. Abdullayeva A.A. Rynok kosmeticheskikh sredstv v rossii: vybor i predpochteniya rossiyan [Cosmetics market in Russia: choice and preferences 
of Russians]. Nauchnoye soobshchestvo studentov XXI stoletiya. Ekonomicheskiye nauki: sb. st. po mat. LXVII mezhdunar. stud. nauch.-prakt. konf. [Scientific community of students of the XXI century. Economic Sciences: Sat. Art. on mat. LXVII Intern. stud scientific-practical conf.]. № 7(67). https://sibac.info/archive/economy/7(67).pdf (accessed: 27.12.2018).

2. Aliyeva Z.M. Kontseptsiya formirovaniya potrebitel'skogo povedeniya pod vliyaniyem marketinga otnosheniy $\mathrm{v}$ roznichnoy torgovle [The concept of the formation of consumer behavior under the influence of the marketing of relations in the retail trade]. TERRA ECONOMICUS. 2013. Vol. 11. №4.2, pp. 92-99.

3. Vakhteyeva D.A. Osobennosti rossiyskogo rynka kosmeticheskikh sredstv [Features of the Russian market of cosmetics]. Molodoy uchenyy. [Young scientist]. 2015. № 21 (101), pp. 367-369.

4. Golovanova Ye. Model' analiza lyuksovykh brendov v internete na primere parfyumerno-kosmeticheskogo rynka [Model of analysis of luxury brands on the Internet on the example of the perfumery and cosmetic market]. Marketingovyye kommunikatsii [Marketing communications]. 2018. №3. pp. 234-242.

5. Krivdina O.A. Aktualizatsiya sovremennykh podkhodov k segmentatsii parfyumerno-kosmeticheskogo rynka [Actualization of modern approaches to the segmentation of the perfumery and cosmetic market]. Sovremennyye tendentsii ekonomiki i upravleniya: Materialy mezhdunarodnoy nauchno-prakticheskoy konferentsii. Kurskiy institut kooperatsii. [Modern trends in economics and management: Materials of the international scientific-practical conference. Kursk Institute of Cooperation]. 2016, pp. 215-219.

6. Makhmudova R. M. Razvitiye parfyumerno-kosmeticheskogo rynka Rossii i reklamnaya aktivnost' [Development of the perfumery-cosmetic market of Russia and advertising activity]. Reklama. Teoriya i praktika [Advertising. Theory and practice]. 2009. №5, pp. 274-284. (In Russian)

7. Nikolayeva M.A., Niy A.A. Analiz sostoyaniya i tendentsiy par-fyumerno-kosmeticheskogo rynka $\mathrm{v}$ Rossii [Analysis of the status and trends of the steam-fumy-cosmetic market in Russia]. Ekonomicheskiye issledovaniya [Economic Research]. 2017. http://www.erce.ru/internet-magazine/magazine/49/706/ (accessed: 27.12.2018). 
8. Fadeyeva T.P., Monakov YU.I. Tendentsii izmeneniya struktury rynka parfyumerno-kosmeticheskikh tovarov v Rossii [Trends in changes in the structure of the market of perfumery and cosmetic products in Russia]. Ekonomika i uprav-leniye $v$ XXI veke: tendentsii razvitiya [Economy and management in the XXI century: development trends]. 2016. № 29, pp. 119-123.

9. Tsvetkova A., Markin I. Prodvizheniye parfyumerno-kosmeticheskikh brendov v segmente rossiyskoy molodezhnoy auditorii [Promotion of perfumery and cosmetic brands in the segment of the Russian youth audience]. Marketingovyye kommunikatsii. [Marketing communications]. 2018. №2, pp. 104-111.

10. Chernitsova M.A. Tendentsii rynka parfyumerno-kosmeticheskoy produktsii za period s 2005 po $2016 \mathrm{gg}$. [Trends in the market of perfumes and cosmetics for the period from 2005 to 2016]. Zhurnal nauchnykh statey Zdorov'ye i obrazovaniye $v$ XXI veke [Journal of scientific articles Health and education in the XXI century]. 2017. Vol. 19. No 8, pp. 189-191.

\section{ДАННЫЕ ОБ АВТОРАХ}

Прохорова Мария Петровна, доцент, канд. педагог. наук, доцент ФГБОУ ВО Нижегородский государственный педагогический университет им. К. Минина

ул. Ульянова, 1, г. Н. Новгород, 603950, Российская Федерация masha.proh@mail.ru

Булганина Светлана Викторовна, доцент, канд. техн. наук, доцент ФГБОУ ВО Нижегородский государственный педагогический университет им. К. Минина

ул. Ульянова, 1, г. Н. Новгород, 603950, Российская Федераџия bulgsv@mail.ru

\section{Булганина Анастасия Евгеньевна, студент}

ФГБОУ ВО Нижегородский государственный педагогический университет им. К. Минина

ул. Ульянова, 1, г. Н. Новгород, 603950, Российская Федераџия bulgsv@mail.ru 
Белоусова Ксения Владимировна, студент

ФГБОУ ВО Нижегородский государственный педагогический университет им. К. Минина

ул. Ульянова, 1, г. Н. Новгород, 603950, Российская Федераџия ksbel99@yandex.ru

\section{DATA ABOUT THE AUTHORS}

Prokhorova Maria Petrovna, Associate Professor, $\mathrm{PhD}$

Nizhny Novgorod State Pedagogical University

1, Ulyanova Str., N. Novgorod, 603950, Russian Federation masha.proh@mail.ru

SPIN-code: 6418-5220

ORCID: 0000-0003-0357-4213

ResearcherID: J-3550-2017

Bulganina Svetlana Viktorovna, Associate Professor, $\mathrm{PhD}$

Nizhny Novgorod State Pedagogical University

1, Ulyanova Str., N. Novgorod, 603950, Russian Federation bulgsv@mail.ru

SPIN-code: 3868-3610

ORCID: 0000-0001-6809-1402

ResearcherID: J-3543-2017

Bulganina Anastasiya Evgenevna, student

Nizhny Novgorod State Pedagogical University

1, Ulyanova Str., N. Novgorod, 603950, Russian Federation bulgsv@mail.ru

SPIN-code: 7336-8091

ORCID: 0000-0003-3300-9469

Belousova Ksenia Vladimirovna, student

Nizhny Novgorod State Pedagogical University

1, Ulyanova Str., N. Novgorod, 603950, Russian Federation ksbel99@yandex.ru

SPIN-code: 2995-6998

ORCID: 0000-0003-3794-4278 